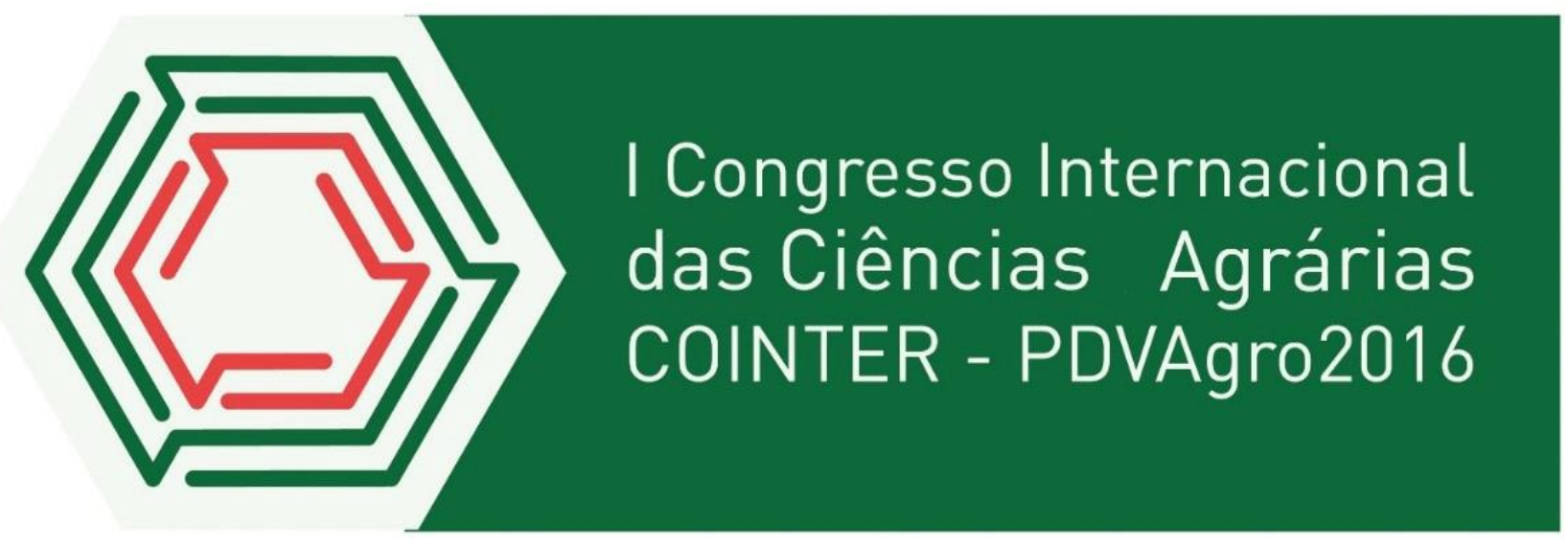

\title{
QUALIDADE SANITÁRIA DE SEMENTES COMERCIAIS DE HELIANTHUS ANNUUS L.
}

\author{
Apresentação: Pôster
}

\begin{abstract}
Roberta Maria Ferreira Paes ${ }^{1}$; Douglas Oliveira Santos ${ }^{2}$; Paulo Sergio da Silva ${ }^{3}$; Denise de Santana Silva ${ }^{4}$; Pablo Radamés Cabral de França 5 .
\end{abstract}

\section{Introdução}

O girassol (Helianthus annuus L.) é uma cultura de crescente valor comercial por ter elevado teor de proteínas e ser uma fonte de óleo vegetal comestível (SILVA, 1990). Pode ser consumida como fruto in natura, na culinária substituindo amêndoas em geral, como farelo (ração) para alimentação de aves, suínos e bovinos, forragem e silagem, para extração de óleo e também como flor ornamental (GAZOLLA et al., 2012).

Entre os fatores que podem limitar a expansão da cultura, podemos destacar a ocorrência de doenças causadas por vírus, bactérias e fungos, sendo o girassol hospedeiro de mais de 35 organismos fitopatogênicos, entre os quais, os fungos apresentam-se em maior percentual (MENTEM, 1985). As principais doenças que afetam a cultura do girassol são transmitidas através das sementes, como Mancha de Alternária (Alternaria helianthi A. zinnae; A. alternata) e a Podridão branca (Sclerotinia sclerotiorum) (LEITE, 2005).

Diante do exposto, objetivou-se com este trabalho determinar uma metodologia para desinfecção de sementes comerciais de $H$. annuus com hipoclorito de sódio.

\footnotetext{
${ }^{1}$ Agronomia, IFPE, robertapaes1@gmail.com

${ }^{2}$ Agronomia, IFPE, douglasoliveira3_@ hotmail.com

${ }^{3}$ Agronomia, IFPE, oualp.sergio1@gmail.com

${ }^{4}$ M. ${ }^{\mathrm{a}}$ Professora, IFPE, deniufrpe@gmail.com

${ }^{5}$ Dr. Pesquisador DCR FACEPE/CNPq, IFPE , pabloradames@ hotmail.com
} 


\section{Fundamentação Teórica}

A semente é o principal insumo para produção de muitas culturas, entre elas o girassol, logo, a qualidade sanitária das sementes é um dos fatores de grande importância no sistema de produção agrícola, ao se levar em consideração os danos que os patógenos encontrados nestas sementes podem ocasionar no desenvolvimento das culturas (BARROCAS \& MACHADO, 2010).

Os gêneros Aspergillus e Penicillium, considerados fungos de armazenamento, também podem ser encontrados associados à sementes de girassol, podendo prejudicar a germinação e a sanidade da cultura no campo ocasionando o desenvolvimento de doenças durante o ciclo da cultura (TALAMINI et al., 2011).

Segundo Coutinho et al. (2000) os tecidos externos, como tegumento e pericarpo, são vistos como uma das principais formas de associação de microrganismos com sementes, para tanto o autor considera que a realização de tratamentos sanitários de sementes, pode controlar a incidência desses patógenos, entre os produtos mais utilizados está o hipoclorito de sódio $(\mathrm{NaClO})$, indicado para sanitização superficiais de material vegetal e de ambientes.

\section{Metodologia}

A presente pesquisa da forma como se configurou apresentou natureza quantitativa do tipo experimental utilizando recursos e técnicas estatísticas transformando informações em números para uma melhor compreensão dos resultados. Para Mattar (2001), a pesquisa quantitativa permite através de uma análise representativa de dados, validar hipóteses utilizando dados estatísticos orientando para um resultado final.

O experimento foi conduzido nos Laboratórios de Semente e de Fitopatologia, ambos pertencentes ao Instituto Federal de Educação Ciência e Tecnologia de Pernambuco (IFPE) Campus Vitória de Santo Antão. Foram utilizadas sementes de girassol de duas variedades identificadas neste trabalho como Comercial I e Comercial II, conhecidas vulgarmente por miúda e graúda, respectivamente. As sementes foram submetidas à desinfecção com três diferentes concentrações de hipoclorito de sódio $\mathrm{NaClO} \mathrm{0,5 \%} \mathrm{(T5,} \mathrm{T6);} \mathrm{1 \%} \mathrm{(T7,} \mathrm{T8)} \mathrm{e} \mathrm{1,5 \%} \mathrm{(T9,} \mathrm{T10);} \mathrm{lavagem} \mathrm{com} \mathrm{água}$ destilada (T3, T4) e mais o tratamento teste (testemunha - T1, T2), totalizando 10 tratamentos. A princípio as sementes foram submetidas ao teste de teor de umidade, sendo determinado pelo método da estufa, a $105^{\circ} \mathrm{C} \pm 3^{\circ} \mathrm{C}$, durante 24 horas (BRASIL, 2009).

Posteriormente as sementes foram submetidas ao teste de sanidade pelo método de incubação (Blotter test), em substrato de papel mata-borrão previamente esterilizado em estufa à 
$120^{\circ} \mathrm{C}$ por $30 \mathrm{~min}$, umedecido e colocado em caixas tipo gerbox com tampas acondicionando 20 sementes em cada, exposto a ação de lâmpadas de luz fluorescente branca, à distância de 30-40 cm, em câmaras de germinação tipo B.O.D com fotoperíodo de 12 horas pelo período de 8 dias e temperatura de $25 \pm 2{ }^{\circ} \mathrm{C}$. Após o período de incubação as sementes foram examinadas individualmente com auxilio de um microscópio óptico para determinação da presença ou ausência de patógenos à nível de gênero.

O delineamento experimental foi inteiramente ao acaso, com quatro repetições de 80 sementes para cada teste. Os dados obtidos foram submetidos à análise de variância, utilizando-se o teste F para comparação dos quadrados médios e as médias comparadas pelo teste de Tukey a 5\% de probabilidade.

\section{Resultados e Discussões}

As variedades avaliadas apresentaram teor de água abaixo de $10 \%$, tendo o lote Comercial I apresentado menor percentual $(6,47 \%)$ e lote da Comercial II maior percentual $(7,18 \%)$ de acordo com a Tabela 1. A umidade ideal para o armazenamento de sementes de girassol deve estar entre 5 e 10\% de acordo com Thomazin \& Martins (2011), que determinaram valor de 7,05\% e concluíram que esta umidade está dentro do padrão ideal para armazenamento. Assim, esta variável não influenciou na qualidade sanitária das sementes em estudo.

Tabela 1. Valores médios do teor de água das sementes Comerciais I e II e de patógenos identificados nas sementes de $H$. annuus submetidas à tratamentos de desinfecção com hipoclorito de sódio, lavagem com água destilada e sem tratamento (testemunha).

\section{Teor de Água (\%)}

\begin{tabular}{lcc}
\hline \multicolumn{1}{c}{ Comercial I } & \multicolumn{2}{c}{ Comercial II } \\
\hline \multicolumn{1}{c}{6,5} & \multicolumn{2}{c}{ Fungos por tratamento (\%) } \\
\hline \multirow{2}{*}{ TRATAMENTOS } & Comercial I & Comercial II \\
\cline { 2 - 4 } & $8 \mathrm{a}$ & $17 \mathrm{a}$ \\
\hline Testemunha & $4 \mathrm{~b}$ & $18 \mathrm{a}$ \\
\hline Hipoclorito de sódio à $\mathbf{0 , 5 \%}$ & $1 \mathrm{c}$ & $5 \mathrm{~b}$ \\
\hline Hipoclorito de sódio à $\mathbf{1 , 0 \%}$ & $0 \mathrm{c}$ & $5 \mathrm{~b}$ \\
\hline Hipoclorito de sódio à $\mathbf{1 , 5 \%}$ & $0 \mathrm{c}$ & $1 \mathrm{c}$ \\
\hline Coeficiente de Variação $(\%)$ & 22,9 & 12,5 \\
\hline
\end{tabular}


Médias seguidas pela mesma letra na coluna, não diferem entre si pelo teste de Tukey, a 5\% de probabilidade

Referente ao percentual dos patógenos identificados em relação aos tratamentos, foi possível observar, a partir dos resultados dispostos na tabela 1, que na variedade Comercial I apenas a lavagem com água destilada demostrou resultado significativo para uma menor incidência de fungo com relação à testemunha, já nos tratamentos com hipoclorito de sódio todos foram significativos com relação a testemunha e a água destilada, mas entre si não diferiram estatisticamente, demostrando que todas as concentrações de hipoclorito foram eficientes. Na variedade Comercial II todos os tratamentos com hipoclorito de sódio foram significativos com relação aos demais tratamentos, sendo que nas concentrações de $\mathrm{NaClO}$, a de 1,5\% apresentou maior eficiência entre as demais concentrações, possivelmente por ser a maior concentração, tendo em vista, que essa variedade comercial apresentou uma maior incidência de fungos. Esses resultados evidenciam a importância do tratamento de sementes na redução da infestação de microrganismos, e a eficiência do hipoclorito de sódio no tratamento de sementes (COUTINHO et al, 2000).

Após o período de incubação foram detectados 12 gêneros de fungos associados a sementes de girassol conforme descrito na Tabela 2. No geral, verificou-se maior incidência em sementes da Comercial II, sendo identificados 26,3\% de Aspergillus sp. e 26,5\% de Rhizopus sp. nas testemunhas de sementes da Comercial I e II, respectivamente. Esses patógenos podem interferir na qualidade fisiológica da semente por ocasionar redução da germinação (SILVA, 2007). Com relação ao gênero Aspergillus sp. segundo Scussel (1998) fungos desse tipo produzem micotoxinas, fato relevante, diante do consumo in natura dessas sementes, podendo oferecer risco toxicológico.

Tabela 2. Incidência (\%) de fungos em sementes de duas variedades de girassol H annus (Comercial I (C I) e Comercial II (C II)) submetidas ao teste de sanidade detectado pelo método Blotter test.

\begin{tabular}{|c|c|c|c|c|c|c|c|c|c|c|}
\hline \multirow{3}{*}{$\begin{array}{c}\text { TRATAMENTOS } \\
\text { GÊNEROS }\end{array}$} & \multirow{2}{*}{\multicolumn{2}{|c|}{ Testemunha }} & \multirow{2}{*}{\multicolumn{2}{|c|}{ Água destilada }} & \multicolumn{6}{|c|}{$\operatorname{NaClO}(\%)$} \\
\hline & & & & & \multicolumn{2}{|c|}{0,5} & \multicolumn{2}{|c|}{1,0} & \multicolumn{2}{|c|}{1,5} \\
\hline & C I & C II & C I & C II & C I & C II & C I & C II & C I & C II \\
\hline Alternaria sp. & 1,3 & 11,3 & - & 10 & - & 1,3 & - & 3,8 & - & - \\
\hline Aspergillus sp. & 26,3 & 16,3 & 16,3 & 21,3 & - & 1,3 & - & - & - & - \\
\hline Bipolares sp. & 3,8 & 7,5 & - & 11,3 & - & 2,5 & - & 1,3 & - & 1,3 \\
\hline Cladosporium sp. & 1,3 & 2,5 & 1,3 & 5,0 & - & 15,0 & - & 6,3 & - & - \\
\hline Colletotrichum sp. & - & 2,5 & - & - & - & - & - & - & - & - \\
\hline Curvularia $\mathrm{sp}$ & - & - & - & - & 1,3 & - & - & - & - & - \\
\hline Fusarium sp. & 2,5 & 17,5 & - & - & - & 3,8 & - & 12,5 & - & 2,5 \\
\hline Lasiodiplodia sp. & - & - & - & - & - & - & - & 2,5 & - & - \\
\hline Nigrospora sp. & - & - & - & 2,5 & - & - & - & - & - & - \\
\hline Penicillium sp. & - & 2,5 & - & - & - & 2,5 & - & - & - & - \\
\hline
\end{tabular}


Embora em ambas as variedades tenham apresentado fungos, apenas na Comercial II houve presença em todos os tratamentos, mas quando submetidas às concentrações de 1 e 1,5\% de hipoclorito de sódio, ocorreu ausência total de fungos nas sementes da Comercial I, constatando que o tratamento sanitário com $\mathrm{NaClO}$ foi capaz de controlar a contaminação desses patógenos eliminando ou reduzindo sua incidência, conforme descrito por Coutinho et al. (2000).

\section{Conclusão}

A desinfecção das sementes com concentrações de $1 \%$ e 1,5\% de hipoclorito de sódio foram eficientes na eliminação e redução de fungos para a variedade Comercial I, enquanto para Comercial II mesmo com a desinfecção, todos os tratamentos apresentaram contaminação fúngica, obtendo menor incidência quando submetidas à concentração de 1,5\%.

\section{Referências}

BARROCAS, E.N.; MACHADO, J.C. Introdução a patologia de sementes e testes convencionais de sanidade de sementes para detecção de fungos fitopatogênicos. Informativo ABRATES, v.20, n.3, p.74-77, 2010.

BRASIL. Ministério da Agricultura, Pecuária e Abastecimento. Regras para análise de sementes. Brasília, DF: MAPA; Secretaria de Defesa Agropecuária, 2009. 399 p.

COUTINHO, W. M.; PEREIRA, L. A. A.; MACHADO, J. C.; FREITAS-SILVA, O.; PENA, R. C. M.; MAGALHÃES, F. H. L. Efeitos de hipoclorito de sódio na germinação de conídios de alguns fungos transmitidos por sementes. Fitopatologia Brasileira, Brasília, v. 25, n. 3, p. 552-555, 2000.

GAZZOLA, A. A cultura do girassol. Piracicaba: EZALQUE/USP, 2012. 63p.

LEITE, R.M.V.B.C. et al. Girassol no Brasil. Empresa Brasileira de Pesquisa Agropecuária. Londrina: EMBRAPACNPSO, 2005. p.641.

MATTAR, F. N. Pesquisa de marketing. 3.ed. São Paulo: Atlas, 2001.

MENTEN, J.O.M. Diagnóstico da Patologia de sementes de girassol no Brasil. Revista Brasileira de Sementes. Brasília, DF. v.07, n.1, 1985.

SCUSSEL, V.M. Micotoxinas em alimentos. Florianópolis: Insular, 1998. 144p.

SILVA, M.N.A. Cultura do girassol. Jaboticabal: FUNEP, 1990. 67p.

SILVA, P. V. et al. Fungos associados às sementes de girassol (Hellianthus annus L.) e capuchinha (Tropaeolum Majus L.) em diferentes condições de armazenamento. Arquivo Instituto Biológico, São Paulo, v. 74, n. 1, p. 3942, 2007. 
TALAMINI, V. et al. Avaliação da qualidade física, fisiológica e sanitária de sementes de girassol introduzidas para cultivo em Sergipe. Aracaju: Embrapa Tabuleiros Costeiros, 2011.

THOMAZIN, A.; MARTINS, L. D. Qualidade física e fisiológica de sementes de girassol (Helianthus annuus L.) cultivar MG2 em condições de casa de vegetação e Laboratório. 